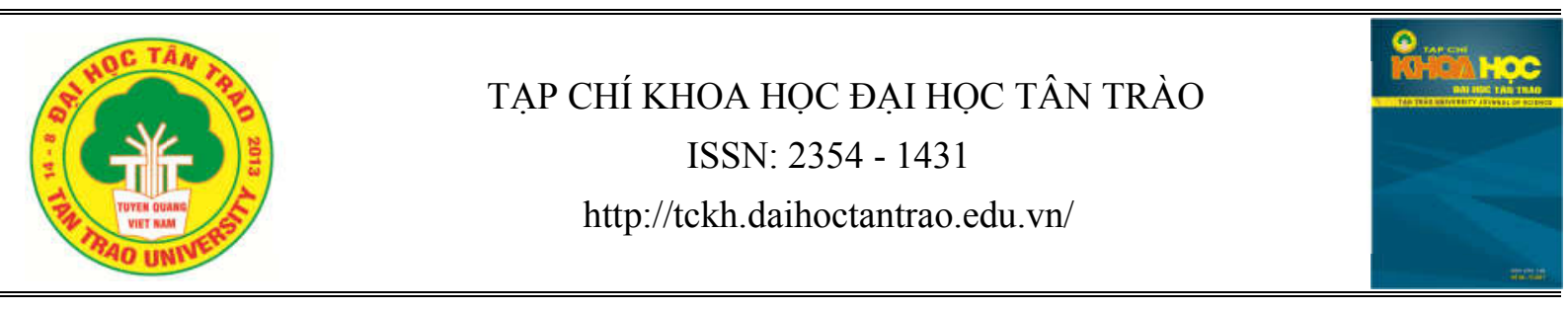

\title{
Hứng thú và môt số kỹ thuật dạy học tạo hứng thú cho sinh viên trong giờ học Tiếng Anh tại Trường đại học Tân Trào
}

Bùi Thị Lan ${ }^{a^{*}}$

${ }^{a}$ Truờng Đại học Tân Trào

*builan.ngoaingu@gmail.com

\section{Thông tin bài viết}

Ngày nhận bài:

$18 / 4 / 2018$

Ngày duyệt đăng:

$12 / 6 / 2018$

\section{Tù̀ khoá:}

Hưng thú, họ tiếng Anh, năng lục, kỹ thuật dạy hoc.

\begin{abstract}
Tóm tắt
Từ nhiều năm nay, tiếng Anh đã trở thành môn học bắt buộc trong các trường Cao đẳng, Đại học. Tiếng Anh cũng là môn học mà rất nhiều em sinh viên đánh giá là khó. Điều này đặt ra yêu cầu cho giáo viên dạy tiếng Anh là làm thế nào để giờ dạy của mình đạt hiệu quả cao và tạo được hứng thú cho người học. Yêu cầu này đòi hỏi người giáo viên phải có năng lực cả về kiến thức chuyên môn và năng lưc sư phạm. Bài viết giúp người đọc có cái nhìn tổng quan về hứng thú và tầm quan trọng của hứng thú trong học tập tiếng Anh, từ đó đề xuất một số kỹ thuật dạy học tạo hứng thú cho sinh viên trong giờ học tiếng Anh tại trường Đại học Tân Trào.
\end{abstract}

\section{Mở đầu}

Việc tìm kiếm phương pháp hiệu quả để khơi dậy và duy trì hứng thú cho người là một vấn đề được quan tâm không chỉ với những người giáo viên mà còn cả đối với những người quản lý giáo dục. Người giáo viên cần làm gì để truyền đạt tốt nhất cho sinh viên, giúp các em hiểu được vấn đề, để bài giảng trở nên phong phú, hấp dẫn, lôi cuốn sự chú ý của sinh viên, giúp các em chủ động tự tin đưa ra những ý kiến đề xuất về nội dung bài học để tiết học thêm sôi nổi. Để sinh viên tham gia vào quá trình hoạt động trí tuệ hiệu quả, có chất lượng đòi hỏi rất nhiều yêu tố ở người dạy và tính tích cực trong học tập của người học. Để khơi dậy được tính tích cực, tự giác của người học thì hứng thú chính là cốt lõi của vấn đề. Tuy hứng thú không phải là khái niệm mới nhưng chúng ta nên có cái nhìn tổng quan về hứng thú dưới góc nhìn và phân tích của các nhà nghiên cứu để hiểu rõ hơn về tầm quan trọng của hứng thú đối với việc học ngoại ngữ, từ đó không ngừng chọn lọc và sáng tạo những phương pháp, thủ thuật mới lôi cuốn người học vào mỗi hoạt động, mỗi bài học một cách hiệu quả nhất.

\section{Nội dung}

\section{1. Định nghĩa về "Hứng thú"}

Hứng thú trong học tập không phải là một chủ đề mới, chính vì vậy đã có rất nhiều định nghĩa, khái niệm về hứng thú. Trên thế giới, nhà tâm lý học Macxit Covaliop A.G (1971) xem xét hứng thú là kết quả của sự hình thành và phát triển nhân cách cá nhân, nó phản ánh một cách khách quan thái độ đang tồn tại ở con người. Tại Việt Nam, theo từ điển bách khoa tiếng Việt: "hứng thú là hình thức biểu hiện tình cảm và nhu cầu nhận thức của con người nhằm ý thức một cách hào hứng về mục đích hoạt động, nhằm tìm hiểu sâu hơn, hiểu biết đầy đủ hơn về vấn đề gây hứng thú”, và “ hứng thú nâng cao mức độ tập trung, chú ý và khả năng làm việc. Khi được làm việc phù hợp với hứng thú, dù phải vượt qua khó khăn, con người vẫn cảm thấy thoải mái và đạt kết quả cao". Trần Thị Minh Đức (1996) đã định nghĩa "Hứng thú là thái độ đặc biệt của cá nhân đối với đối tượng nào đó vừa có ý nghĩa đối với cuộc sống vừa có khả năng đem lại khoái cảm cho cá nhân trong quá trình hoạt động". Phạm Minh Hạc - Lê Khanh - Trần trọng Thủy (1998) cũng khẳng định "Khi ta hứng thú về một cái gì đó 
bao giờ cũng được ta ý thức, ta hiểu ý nghĩa của nó đối với cuộc sống của ta. Hơn nữa ở ta xuất hiện một tình cảm đặc biệt đối với nó, do đó hứng thú lôi cuốn hấp dẫn chúng ta về phía đối tượng của nó tạo ra tâm lý khát khao tiếp cận đi sâu vào nó"

\section{Tầm quan trọng của hứng thú trong học tập}

Hứng thú đối với học tập nói chung và học ngoại ngữ nói riêng rất quan trọng, sự cần thiết của sự hứng thú trong học tập không chỉ dừng ở ý nghĩa đơn thuần là sinh viên đó chăm chú nghe giảng mà còn thể hiện ý nghĩa sâu xa là khi người học có hứng thú về một lĩnh vực nào đó, nó sẽ trở nên dễ dàng thậm chí còn mang lại sự hứng khởi, niềm đam mê, thích thú khi được học môn học này.

Khi nói về tầm quan trọng của hứng thú trong học tập, đã có rất nhiều nghiên cứu chỉ ra vai trò và sự đóng góp đáng kể của hứng thú. Theo P.A. Rudich (1986) trong hoạt động học tập và nghiên cứu, sự xuất hiện hứng thú là đặc biệt quan trọng. Trong trường hợp đó, hứng thú được xác định như một xu hướng của cá nhân có kèm theo những cảm xúc tốt trong quá trình thoả mãn nhu cầu đối với một thông tin mới, trước hết và chủ yếu là nhờ các cảm giác trí tuệ như ngạc nhiên, ước đoán, tính rõ ràng, lòng tin tưởng. Theo Hidi (1990) cho rằng hứng thú là một yếu tố thúc đẩy quá trình học tập, do đó người học đạt được kết quả học tập tốt hơn. Nhiều nghiên cứu đã chỉ rõ hứng thú cá nhân giúp người học tăng cường sự tập trung, gợi nhớ lại kiến thức, tính kiên nhẫn đối với bài tập được giao và sự nỗ lực để đạt được mục đích

Rõ ràng cả nhà nghiên cứu trong và ngoài nước đều nhận định rằng hứng thú là một nhân tố rất quan trọng, thúc đẩy con người có niềm khao khát được tiếp cận với khách thể, từ đó thúc đẩy hành động tích cực, hiệu quả. Như vậy, chúng ta có thể thấy rằng trong quá trình học nói chung nếu sinh viên có hứng thú với môn học thì tự trong ý thức của các em sẽ hình thành động cơ học tập đúng đắn và khát khao thực hiện được mục tiêu học tập đã đề ra. Hứng thú học tập chính là thái độ nhận thức đặc biệt của chủ thể đối với hoạt động học tập. Nhờ hứng thú sinh viên có thể giảm mệt mỏi, căng thẳng, tăng sự chú ý, thúc đẩy tính tích cực tìm tòi, sáng tạo trong quá trình học tập và dễ dàng lĩnh hội nguồn tri thức hơn.

Ngoài ra, hứng thú học tập còn liên quan mật thiết đến động cơ học tập. Động cơ học tập không có sẵn hay tự phát, mà được hình thành dần dần trong quá trình học tập của sinh viên dưới sự tổ chức, hướng dẫn của giáo viên. Nhu cầu giải quyết được mâu thuẫn "giữa một bên là "phải hiểu biết" và bên kia là "chưa hiểu biết" (hoặc hiểu biết chưa đủ, chưa đúng)" là nguyên nhân chính yếu để hình thành động cơ học tập ở học sinh.

Động cơ nói chung và động cơ học tập nói riêng thường liên hệ chặt chẽ tới hứng thú của mỗi người. Nhờ có hứng thú mà động cơ ngày càng mạnh mẽ. Vì thế vai trò của hứng thú trong học tập là rất lớn. Trong học tập chẳng những cần có động cơ đúng đắn mà còn phải có hứng thú bền vững thì học sinh mới có thể tiếp thu tri thức hiệu quả nhất. Khi xét về động cơ học tập ngôn ngữ của người học, Cole và Chan (1994) đề cập đến hai động cơ chính đó là động cơ bên ngoài và động cơ bên trong. Động cơ bên ngoài liên quan đến những yếu tố bên ngoài lớp học. Những yếu tố bên ngoài lớp học có thể là do nhu cầu của người học nhằm đạt được mục tiêu của cá nhân như để giao tiếp hiệu quả, để thuận lợi trong quá trình xin việc hoặc được cân nhắc ở vị trí cao hơn trong công việc.... Đồng thời yếu tố bên ngoài lớp học còn là sự hấp dẫn từ nền văn hóa của cộng đồng sử dụng ngôn ngữ mà người học đang hướng tới. Người học hào hứng tìm hiểu và hội nhập vào nền văn hóa đó.

Động cơ bên trong liên quan đến các nhân tố bên trong lớp học. Động cơ này đóng một vai trò quan trọng trong việc quyết định thái độ học tập của sinh viên. Một sinh viên không có động cơ học tập bên ngoài vẫn có thể có thái độ học tập tích cực và đạt kết quả tốt trong học tập. Động cơ bên trong bị ảnh hưởng bởi bốn yếu tố chính: thứ nhất là điều kiện vật chất của lớp học, trang thiết bị dạy và học, môi trường xung quanh và quy mô lớp học; thứ hai là phương pháp giảng dạy - một yếu tố quyết định đối với sự yêu thích môn học của sinh viên; thứ ba là tính cách, kiến thức và sự nhiệt tình của giáo viên; cuối cùng là sự thành bại của sinh viên trong học tập.

Đúng vậy, theo kết quả của nhiều nghiên cứu đã cho thấy người học có khả năng học nhiếu kiến thức đến mức kinh ngạc về những gì hấp dẫn họ; não bộ của chúng ta có khả năng tiếp thu khối lượng kiến thức đặc biệt khi có hứng học lĩnh vực nào đó; đây cũng là lý do tại sao sinh viên cần phải có hứng thú trong học tập. Khi họ có hứng thú học môn học cụ thể nào đó, sinh viên kể cả những người lớn tuổi đều học tốt hơn nếu họ quan tâm đến những nội dung kiến thức mà họ đang học. 


\section{Khảo sát thực trạng}

Để có cái nhìn khách quan hơn về vấn đề, tác giả đã khảo sát 79 sinh viên K4 Đại học Tiểu học về mức độ hài lòng của các em khi học môn tiếng Anh tại nhà trường. Các câu hỏi trong bảng hỏi là các yếu tố ảnh hưởng đến hứng thú học tập của sinh viên đối với môn Bảng hỏi khảo sát tiếng Anh. Các yếu tố này bao gồm yếu tố khách quan về nội dung, giáo trình, tài liệu,cơ sở vật chất, không khí lớp học, giáo viên... và các yếu tố chủ quan liên quan đến người học như phương pháp, năng lực tiếng Anh, nhận thức về tầm quan trọng môn học, kiến thức nền và ý thức tự giác, tích cực học tập.

\begin{tabular}{|c|c|c|c|c|c|}
\hline \multirow[b]{2}{*}{ Câu hỏi khảo sát } & \multicolumn{5}{|c|}{ Mức độ hài lòng } \\
\hline & $\begin{array}{l}\text { Rất không } \\
\text { hài lòng }\end{array}$ & $\begin{array}{l}\text { Không hài } \\
\text { lòng lắm }\end{array}$ & $\begin{array}{l}\text { Bình } \\
\text { thường }\end{array}$ & $\begin{array}{l}\text { Khá hài } \\
\text { lòng }\end{array}$ & Rất hài lòng \\
\hline \multicolumn{6}{|l|}{ Các yếu tố khách quan } \\
\hline $\begin{array}{l}\text { 1. Giáo trình, tài liệu học tập mới, phù hợp với trình } \\
\text { độ của bạn }\end{array}$ & 4 & 56 & 16 & 3 & 0 \\
\hline 2. Nội dung các bài học phong phú, cập nhật. & 0 & 4 & 63 & 2 & 0 \\
\hline 3. Không khí lớp học sôi nổi & 3 & 12 & 57 & 10 & 0 \\
\hline $\begin{array}{l}\text { 4. Phòng học và trang thiết bị phòng học phục vụ } \\
\text { dạy học tốt }\end{array}$ & 0 & 1 & 11 & 67 & 0 \\
\hline 5. Giảng viên có trình độ tiếng Anh tốt & 0 & 0 & 20 & 59 & 0 \\
\hline $\begin{array}{l}\text { 6. Giảng viên thường xuyên ứng dụng CNTT trong } \\
\text { giảng dạy }\end{array}$ & 0 & 13 & 16 & 50 & 3 \\
\hline 7. Giảng viên có phương pháp truyền đạt dễ hiểu & 0 & 23 & 56 & 0 & 0 \\
\hline 8. Giảng viên giảng dạy nhiệt tình, vui vẻ & 0 & 0 & 55 & 20 & 4 \\
\hline 9. Giảng viên sử dụng nhiều hoạt động đa dạng trên lớp & 0 & 16 & 49 & 14 & 0 \\
\hline $\begin{array}{l}\text { 10. Giảng viên thường xuyên hướng dẫn sinh viên } \\
\text { cách tự học, các phương pháp học ngoại ngữ hiệu } \\
\text { quả }\end{array}$ & 0 & 20 & 45 & 14 & 0 \\
\hline $\begin{array}{l}\text { 11. Giảng viên chú trọng phát triển khả năng giao } \\
\text { tiếp cho sinh viên }\end{array}$ & 0 & 40 & 25 & 14 & 0 \\
\hline \multicolumn{6}{|l|}{ Các yếu tố chủ quan } \\
\hline 12. Bản thân bạn có phương pháp học ngoại ngữ tốt & 29 & 30 & 20 & 0 & 0 \\
\hline $\begin{array}{l}\text { 13. Bản thân bạn có trình độ tiếng Anh cơ bản đáp } \\
\text { ứng điều kiện tiên quyết của môn học tại trường. }\end{array}$ & 53 & 10 & 15 & 1 & 0 \\
\hline $\begin{array}{l}\text { 14. Bản thân bạn nhận thức được tầm quan trọng } \\
\text { của môn học }\end{array}$ & 0 & 4 & 15 & 50 & 10 \\
\hline $\begin{array}{l}\text { 15. Bản thân bạn có hứng thú, mong muốn được } \\
\text { học môn Ngoại ngữ. }\end{array}$ & 0 & 39 & 21 & 19 & 0 \\
\hline
\end{tabular}


Nhìn vào bảng số liệu điều tra, ta thấy ở nhóm yếu tố khách quan, khi được hỏi về giáo trình, tài liệu đang học chỉ rất ít số sinh viên được hỏi $(03)$ em là cảm thấy khá hài lòng với giáo trình học tập, gần $3 / 4$ các em trả lời chưa cảm thấy hài lòng. Khi được phỏng vấn sâu về giáo trình các em trả lời là giáo trình nhà trường đang sử dụng là khó với trình độ các em.

Về phòng học và trang thiết bị phòng học là yếu tố có tỉ lệ sinh viên cảm thấy hài lòng cao nhất $(84,8 \%)$, số còn lại được đánh giá ở mức độ bình thường. Tuy nhiên, không khí học tập trong lớp còn chưa đáp ứng được mong muốn của sinh viên, thể hiện ở chỗ chỉ $12 \%$ sinh cảm thấy hài lòng và rất hài lòng; $72 \%$ sinh viên cảm thấy bình thường và khoảng $15 \%$ chưa hài lòng.

- Về người dạy:

Về kiến thức của người dạy: Năng lực tiếng Anh của $\mathrm{GV}$ được sinh viên đánh giá với tỉ lệ hài lòng cao, có 59 em tương đương 74,6\%; chỉ có 20 sinh viên đánh giá hài lòng ở mức trung bình. Về phương pháp giảng dạy của người dạy: khả năng ứng dụng CNTT trong giảng dạy và giảng viên giảng dạy nhiệt tình, vui vẻ là 2 yếu tố liên quan đến người dạy được sinh viên đánh giá hài lòng ở mức độ cao. Không có sinh viên nào đánh giá không hài lòng về khả năng ứng dụng CNTT của giảng viên và về sự nhiệt tình, vui vẻ của giảng viên khi giảng dạy. Trong khi đó, các yếu tố GV có phương pháp truyền đạt dễ hiểu, GV sử dụng đa dạng các hoạt động trên lớp là chưa nhận được nhiều phản hồi tích cực từ phía người học. Tỉ lệ sinh viên đánh giá ở mức rất hài lòng là chưa có. gần $3 / 4$ sinh viên đánh giá phương pháp truyền đạt dễ hiểu ở mức bình thường và một số ít sinh viên không hài lòng.

Mặt khác, xét về yếu tố chủ quan,các em sinh viên cũng chưa có phương pháp học ngoại ngữ hiệu quả. Có đến 29 em chọn mức độ rất không hài lòng với phương pháp của bản thân và chỉ có rất là chọn ở mức độ hài lòng. Theo bảng số liệu đa số các em tự nhận thấy trình độ tiếng Anh của các em chưa đáp ứng được điều kiện tiên quyết của môn học nhưng điều đáng nói là các em chưa có hứng thú với môn học ngoại ngữ, có đến nửa số sinh viên được điều tra chưa có hứng thú và chỉ có 19 em là có hứng thú.

\section{Một số kỹ thuật day học tạo hứng thú cho sinh viên trong giờ học tiếng Anh}

Từ thực trạng trên, về phía người dạy, tác giả xin được chia sẻ một số kỹ thuật dạy học gây hứng thú cho sinh viên trong giờ học Tiếng Anh tại trường Đại học Tân Trào.

\subsection{Nắm vũ̃ng kiến thức và linh hoạt trong các bước lên lớp.}

Đối tương chúng ta hướng đến là sinh viên nên phương pháp giảng dạy chúng ta luôn lấy sinh viên làm trung tâm, để sinh viên phải vận động suy nghĩ tìm tòi chiếm lĩnh tri thức một cách chủ động tích cực. Điều đó không có nghĩa là phủ nhận vai trò của người thầy mà ngược lại thầy cô có vai trò rất quan trọng trong việc tổ chức, điều khiển quá trình học. Để có thể điều khiển các hoạt động trên lớp một cách hợp lý, có hiệu quả đòi hỏi người giáo viên phải có năng lực, kiến thức vững vàng, có phương pháp sư phạm và linh hoạt trong các bước lên lớp.

Trước hết, sở hữu kiến thức vững vàng là chìa khóa đầu tiên để có thể điều khiển các hoạt động trên lớp một cách hợp lý, có hiệu quả. Sinh viên luôn ngưỡng mộ và thích thú học những thầy cô có kiến thức sâu rộng, có kỹ năng tổ chức và giải quyết các vấn đề có thể giúp học sinh giải đáp những thắc mắc.Nhờ có kiến thức vững vàng sâu rộng thì đứng trước sinh viên, giáo viên mới có thể tự tin và chủ động trong việc giảng dạy và truyền tải kiến thức chính xác khoa học. Sự tự tin đóng vai trò rất lớn trong sự thành công. Sự tự tin có thể gây được cảm hứng, sự say mê, hứng thú cho người nghe, người tiếp xúc với chúng ta. Đối tượng sinh viên mỗi lớp của chúng ta không nhỏ, thậm trí có lớp tới 50 hay 59 sinh viên và các em đang cần thầy cô thổi một luồng không khí mới để các em có thể chút bỏ sự sợ hãi, sự mệt mỏi, căng thẳng với môn học vốn đã được mặc định là khó. Để có được sự tự tin trên bục giảng đòi hỏi thầy cô phải có kiến thức, không ngừng học hỏi, đổi mới phương pháp, nghiên cứu tài liệu tham khảo, học hỏi kinh nghiệm từ đồng nghiệp. Soạn bài cẩn thận, tiên đoán các vấn đề có thể xảy ra trên trước khi đến lớp.

Bên cạnh đó, để có những tiết dạy hiêu quả, giảm căng thẳng thì giáo viên phải hiểu tâm lý học sinh, và 
quan trọng hơn là thiểu biết đối tượng và dạng bài dạy để giáo viên linh hoạt trong các bước lên lớp. Chúng ta không nhất thiết phải tuân theo tiến trình của phương pháp dạy một cách cứng nhắc.

Ví dụ, chúng ta thường kiểm tra bài cũ trước khi và bài mới làm học sinh cảm thấy căng thẳng, áp lực, mất hứng thú với bài học. Do đó chúng ta không nhất thiết phải kiểm tra bài cũ mà có thể kiểm tra bất cứ lúc nào hợp lý trong bài học khi chúng ta đưa ra vấn đề mà học sinh trả lời được, nhắc lại được như thế sẽ tạo được không khí thoải mái hơn. Thay vào việc gọi một hoặc hai học sinh lên nhắc lại kiến thức cũ hay làm bài tập về nhà thì ta có thể lồng ghép các trò chơi, vừa củng số kiến thức cũ vừa liên quan tới bài mới để dẫn dắt chủ đề của bài mà ta sắp dạy thì học sinh sẽ hứng thú hơn, tập trung vào bài hơn.

Ngoài ra khi chuyển từ phần này sang phần khác chúng ta cần có những câu nối, dẫn dắt phù hợp gây sự chú ý, tò mò cho học sinh để học sinh cảm thấy các phần trong bài không rời rạc mà rất logic và cần phải tìm hiểu các phần tiếp theo để hiểu bài một cách thấu đáo. Làm được như vậy thì không gì khác ngoài việc giáo viên phải vững vàng kiến thức, các dạng, kiểu bài lên lớp và am hiểu học sinh cả về tâm lý và trình độ để vận dụng sao cho linh hoạt, phù hợp với đối tượng để đạt hiệu quả cao nhất.

\subsection{Vào bài hấp dẫn}

Để có thể gây được sự chú ý, lôi cuốn học sinh ngay từ hoạt động đầu tiên, đem lại hứng thú cho sinh viên, giáo viên cần lưu ý một số điểm sau:

+ Trình độ sinh viên: Nếu sinh viên đa phần khá thì ta có thể chọn hoạt động có độ khó, thách thức cao hơn thay vì lựa chọn những hoạt động nên đơn giản và dễ hơn đối với học sinh đa phần là trung bình - yếu. Sau đây là một số cách vào bài gây hứng thú cho sinh viên trong giờ tiếng Anh:

- Sử dụng trò chơi: Đây là cách sinh viên thích thú nhất.

Ví dụ: Để dẫn dắt vào Unit 10 , giáo trình Life lines Intermediate, giáo viên cho sinh viên chơi trò chơi đoán từ dựa vào các gợi ý, sau đó yêu cầu sinh viên đoán chủ đề của bài học về gì.

Giáo viên: It is a noun

This word consists of 6 lettets
It seems that it is the most important things we want....

Leading unit 10: Health

- Hát: Bài hát sát với chủ đề.

Ví dụ: Để dẫn dắt vào tiết từ vựng Unit 10 , giáo trình Life lines Intermediate, giáo viên bật video bài hát What's the matter cho sinh viên nghe sau đó yêu cầu sinh viên trả lời các câu hỏi về nội dung bài hát.

What's the matter with the boy? - He has a bad cough

Did he go to school? - No, he didn't

Where did his mother take him to? The doctor

What did the doctor say? - He should stay in bed and shouldn't drink cold water

$\Rightarrow$ Medical term

\subsection{Biết cách gợi mở, tháo gõ̃ khó khăn}

Đặc điểm sinh viên ở trường là đa số các em học chưa tốt môn Tiếng Anh, các em rất sợ phải đối mặt với các bài đọc dày đặc chữ. Do đó giáo viên phải biết cách gợi mở để giảm bớt khó khăn, để sinh viên không cảm thấy khó và chán nản. Có nhiều cách gợi mở khác nhau tuỳ từng yêu cầu mà ta gợi ý cho sinh viên.

Với một bài đọc hiểu hay một bài nghe khó thì việc gợi mở, tháo gỡ khó khăn ở đây là ta phải chọn được những từ ngữ, cấu trúc mới quan trọng cần thiết cho việc giao tiếp của sinh viên mà sinh viên không đoàn nghĩa được để dạy. Khi sinh viên nắm được các từ, cấu trúc này rồi thì việc đọc hay việc nghe hiểu trở nên dễ dàng hơn rất nhiều. Việc tiếp theo là khi giao nhiệm vụ cho sinh viên nên hướng dẫn cho sinh viên cách làm để học sinh hoàn thành nhiệm vụ một cách nhanh nhất và chính xác.

Đối với những câu hỏi, lời nói khó hiểu thì giáo viên nên gợi mở bằng cách yêu cầu các em gạch chân những từ quan trọng (key words) trong câu đó rồi bảo các em chú ý vào các từ đó. Nếu sinh viên vẫn chưa hiểu thì giáo viên sẽ giải thích.

Giáo viên tiếng Anh cần phải tận dụng mọi cơ hội để gợi mở cho sinh viên luyện nói nhiều hơn bất cứ giáo viên môn nào khác. Đặt câu hỏi là hình thức rộng rãi nhất để gợi mở cho sinh viên nói, nhưng đó không phải là cách duy nhất. Mà ta phải dùng các thủ thuật để lôi cuốn, thu hút được toàn bộ sinh viên trong lớp 
và cung cấp cho sinh viên những cơ hội để chính họ tự đưa ra câu hỏi. Bản thân giáo viên sẽ trả lời các câu hỏi hoặc cũng có thể gọi 1 sinh viên lên trước lớp để trả lời.

\subsection{Hoạt động trong lớp phải đa dạng.}

- Nếu cả một tiết học chỉ có một, hai hoạt động thôi thì sinh viên sẽ cảm thấy rất tẻ nhạt và nhàm chán. Chính vì vậy hoạt động trong lớp chúng ta nên tổ chức phong phú. Để sinh viên có hứng thú hơn ta nên tổ chức đa dạng các hoạt động từ cá nhân, cặp, nhóm để tham gia vào các trò chơi, cuộc thi nhỏ. Các câu trả lời được chấm điểm dựa vào độ chính xác về ngôn ngữ cũng như thông tin. Chúng ta phải hiểu rằng sự thay đổi các hoạt động trong học tập giúp sinh viên duy trì được sự tập trung, chú ý của các em. Qua các hoạt động này sinh viên cũng ý thức hơn được rằng bản thân chúng có quyền tự chủ và trách nhiệm đối với sự tiến bộ của chúng.

- Có một số hoạt động trong lớp như: làm việc cá nhân, theo cặp: Giáo viên -sinh viên ; sinh viên -sinh viên ; theo nhóm: làm việc cả lớp. Trong đó việc tổ chức luyện tập ngoại ngữ theo cặp/nhóm có ý nghĩa rất quan trọng, giúp cho sinh viên bạo dạn hơn trong việc sử dụng tiếng Anh vì sinh viên yếu thường lo sợ sẽ mắc lỗi trước mặt thầy cô nhưng nếu chỉ có các bạn cùng lớp thì sự e dè đó sẽ ít hơn nhiều. Sinh viên sẽ vượt qua được những nhược điểm về tính cách của bản thân để học tốt hơn. Ngoài ra sinh viên cũng có cơ hội để giúp đỡ, học hỏi nhau nhiều hơn..

\subsection{Sử dụng tốt các phuơng tiện dạy học.}

Ngay từ khi soạn bài, giáo viên cần cân nhắc, lựa chọn các phương tiện để đạt được mục tiêu bài dạy hiệu quả nhất, ví dụ như tranh ảnh minh hoạ, vật thật: đài, đĩa, đầu máy video, máy chiếu... Dù những thiết bị này làm cho bài dạy của giáo viên sinh động hơn, lôi cuốn được sự chú ý của học sinh hơn nhưng không phải phương tiện nào cũng hữu hiệu với tất cả các bài học.

Một trong những vật dụng mà chúng ta hay dùng đó là tranh ảnh. Thầy cô nên lựa chọn những tranh, hình ảnh mang tính giáo dục, thẩm mỹ. Tránh những bức tranh phản cảm, không có tính giáo dục và kích cỡ tranh phải phù hợp để học sinh dễ quan sát. Với tranh thì thầy cô chuẩn bị cả nam châm hoặc dây treo, đinh treo. Giáo viên gắn nam châm hoặc đinh treo lên vị trí phù hợp trước để ta không bị lúng túng và mất thời gian khi tiết học đang diễn ra. Lựa chọn thời điểm thích hợp mới đưa tranh ra, sau khi sử dụng xong phải thu gọn để sinh viên không bị phân tán sự tập trung vào bài giảng.

\subsection{Biết cách phát huy tác dụng của các trò chơi}

\section{đúng lúc.}

Không phải học sinh bé mới thích chơi trò chơi, thực tế sinh viên luôn cảm thấy căng thẳng khi giờ học kéo dài với các hoạt động rập khuôn theo giáo trình. Vì thế giáo viên cần biết vận dụng các trò chơi để củng cố lại kiến thức, giới thiệu bài mới hay ghi nhớ hay luyện tập cho sinh viên thì sinh viên sẽ rất hứng thú, quên đi sự mệt mỏi, chán nản trong giờ học. "Học mà chơi, chơi mà học", đó là tinh thần học tập thông qua các trò chơi. Ở đây tác giả đã tổng hợp lại các trò chơi để các giáo viên có thể "tùy cơ ứng biến”, vận dụng chúng sao cho phù hợp với đối tượng, phù hợp với mục tiêu của tiết dạy để đem lại kết quả cao. Sau đây là một số trò chơi rất dễ áp dụng:

\subsubsection{Jumbled words:}

- Giáo viên viết một số từ có các chữ hoặc một số câu bị xáo trộn lên bảng.

- Yêu cầu sinh viên sắp xếp lại thành từ hoặc câu có nghĩa.

+ Giáo viên có thể sử dụng trò chơi này khi muốn kiểm tra từ vựng hoặc cấu trúc ngữ pháp. Hình thức kiểm tra từ vựng hoặc cấu trúc ngữ pháp dưới dạng trò chơi này thích hợp với hầu hết các bài và không gây áp lực "kiểm tra" cho sinh viên.

\subsubsection{Word square:}

- Giáo viên viết ô chữ lên bảng hoặc chuẩn bị sẵn trên bìa.

- Nêu chủ điểm của các từ và số lượng từ cần tìm trong ô chữ.

-Chia lớp ra thành 2 nhóm. Mỗi nhóm cử đại diện lên bảng khoanh tròn các từ tìm thấy(theo hàng ngang,dọc,chéo).

- Nhóm nào tìm được nhiều từ hơn thì thắng.

+ Thầy cô nên áp dụng trò chơi này khi day xong một, hay một số chủ đề.

+ Thầy cô nên chuẩn bị sẵn trên bìa hoặc bảng phụ. 


\subsubsection{Lucky numbers:}

- Chia lớp thành các 2 nhóm

- Giáo viên viêt lên bảng một vài con số

- Trong các số đó có số may mắn mà Giáo viên đã bí mật ấn định trước. VD 3, 5

- Các nhóm lần lượt được gọi số,nếu vào số may mắn sẽ được gấp đôi số điểm quy định cho mỗi câu.Nếu nhóm nào trả lời sai,nhóm khác có quyền trả lời tiếp câu hỏi đó.

- Khi các số đã được chọn hết, nhóm nào có nhiều điểm hơn là nhóm chiến thắng

\subsubsection{Nought and crosses (Question game)}

Đây là một trò chơi giống với chơi cờ carô. Giáo viên có thể áp dụng trò chơi này ở cuối mỗi một bài học. Khi chơi trò chơi này sẽ giúp học sinh ôn tập, củng cố nội dung bài học và học sinh có cơ hội luyện nói. Giáo viên chuẩn bị một khung ô trên bảng như trò chơi cờ carô. Điền một từ vào mỗi ô của khung. Lớp học được chia đều thành hai đội chơi. Một đội dùng kí hiệu "Nought" $(\mathrm{O})$ và đội kia dùng "crosses" $(\mathrm{X})$. Mỗi bên sẽ lần lượt đặt một câu hỏi.

Với một câu hỏi đúng GV yêu cầu đội đó điền "nought" hoặc “crosses" vào khung. Đội đầu tiên đạt được 3 dấu (o) hoặc 3 dấu $(\mathrm{X})$ trên cùng một hàng sẽ là đội thắng. Sau mỗi câu hỏi của đội nàythì đội kia có cơ hội trả lời. Nếu trả lời đúng thì đội đó sẽ được một điểm. Nếu không có đội nào đạt được 3 dấu $(\mathrm{O})$ hoặc $\mathrm{X}$ ) trên cùng một hàng thì sẽ xét điểm trả lời. Và đội nào đạt điểm trả lời đúng nhiều hơn sẽ thắng cuộc. GV có thể chọn một chủ đề chung nào đó hoặc chọn theo bài học.

\section{5. Động viên người học tham gia các hoạt động có sử dụng tiếng Anh}

Giáo viên nên động viên sinh viên tham gia các hoạt động chính khóa và ngoại khóa do trường, các đoàn thể, câu lạc bộ có sử dụng Tiếng Anh. Hiện nay, nhà trường đang tạo rất nhiều cơ hội cho các em được tiếp xúc, giao lưu, thực hành ngoại ngữ như chương trình Thực tập sinh quốc tế, nơi các em được sống và thực hành tiếng tại các nước như Philippine, Thái lan... Câu lạc bộ Tiếng Anh do Hội Sinh viên thành lập, nơi các em được chia sẻ kinh nghiệm, phương pháo học tiếng Anh, Hội sinh viên tình nguyện Quốc tế, nơi các em có thể thực hành tiếng Anh với người bản ngữ khi các em tham gia hoạt động đưa, đón đoàn khách quốc tế của nhà trường, các chương trình Giao lưu văn hóa quốc tế, chương trình Hè trải nghiệm...

\section{KẾT LUẬN}

Tóm lại, hứng thú của chủ thể đối với hoạt động học tập vô cùng quan trọng, quyết định đến chất lượng tiếp nhận thông tin và chuyển hóa thông tin thành các kỹ năng và kinh nghiệm vận dụng trong cuộc sống một cách thành thạo và hiệu quả. Có hứng thú, người học sẽ không ngừng nỗ lực, sẽ biết kết hợp các yếu tố bên trong và bên ngoài để mang lại sự khoái cảm cho cá nhân trongtrong quá trình học tập. Vì vậy các giáo viên cần tận dụng sự hứng thú của sinh viên để thúc đẩy sinh viên học tập. Tùy từng nội dung bài học, từng đối tượng sinh viên để "tùy cơ ứng biến", vận dụng những phương pháp, thủ thuật thích hợp nhất nhằm tạo hứng thú học tập cho sinh viên và giúp sinh viên phát triển niềm đam mê học tập khi họ thiếu vắng sự hứng thú.

\section{TÀI LIỆ THAM KHẢO}

1. Cole, P.G. \& Chan L (1994), Teaching Principles and Practice, Australia: Prentice Hall of Australia Pty Ltd.p;

2. Đỗ Thị Châu (2000), Khái niệm hứng thú và nhũ̃ng yêu cầu trong dạy học môn ngoại ngũu, Tạp chí Đại học và Giáo dục chuyên nghiệp, Số 5, trang 25 - 27;

3. "Nghiên cúu về thái độ học tập" (đăng ngày 17/7/2005) trên diễn đàn của trang web Tâm lý học và bạn: http://www.tamlyhoc.net/forum/index.php?topic $=653.0$;

4. Các yếu tố ảnh hưởng đến hứng thú học ngoại ngũu, from http://ngoaingu.hlu.edu.vn/SubNews/Details/16867;

5. Hứng thú - Khái niệm hứng thú trong tâm lý hoc, http://butnghien.com/hung-thu-khai-niem-hungthu-trong-tam-ly-hoc.t4401/;

6. Phạm Minh Hạc - Lê Khanh - Trần trọng Thủy Retrieved from www.cmard2.edu.vn;

7.Trần Thị Minh Đức - $\quad$ Retrieved from www.cmard2.edu.vn. 


\section{Interest and some skills of drawing interest For students In foreign language learning}

Bui Thi Lan

\section{Article info}

Recieved:

$18 / 4 / 2018$

Accepted:

$12 / 6 / 2018$

Keywords:

Excitement, foreign

language, competence, methods, techniquies.

\begin{abstract}
For many years, foreign language has become one of the compulsory subjects in colleges and universities. Foreign language is also a subject that many students find it difficult to learn. This sets the requirement for foreign teachers that how to make their teaching lessons more effective and how to motivate learners. This also requires teachers to be competent not only in the professional level but also in teaching methods and teaching techniques. The article gives an overview of the excitement and the importance of excitement in learning foreign language; it also proposes some techniquies to inspire students in learning English at Tan Trao University.
\end{abstract}

